\title{
Student Preferences and Expectations: Some Practical Tips for Designers of English Enhancement Programmes
}

\author{
Marine Yeung ${ }^{1} \&$ Tilo $\mathrm{Li}^{2}$ \\ ${ }^{1}$ School of Arts and Humanities, Tung Wah College, Hong Kong \\ ${ }^{2}$ School of Business, Tung Wah College, Hong Kong \\ Correspondence: Marine Yeung, School of Arts and Humanities, Tung Wah College, 90A, Shantung Street, \\ Mongkok, Kowloon, Hong Kong. Tel: 852-34686694. E-mail: marineyeung@twc.edu.hk
}

Received: November 12, 2017 Accepted: January 22, 2018 Online Published: January 24, 2018

doi: $10.5539 /$ elt.v11n2p172

URL: http://doi.org/10.5539/elt.v11n2p172

\begin{abstract}
As one of the essential skills for success in work and studies, English communication is often made a key component in the GE curriculum of tertiary study programmes. In addition to the provision of required English proficiency courses, many tertiary institutions have established English centres of some description to promote English learning on campus. Yet from students' perspective, what kinds of programmes and activities should be offered, and how they feel about these initiatives is not very widely discussed in the existing literature.

This paper aims to address these questions with practical experiences gained from a project to establish an English language enhancement centre by one self-financing tertiary institution in Hong Kong. Funded by the Quality Enhancement Support Scheme (QESS), the centre, titled the Centre for Academic and Professional Language Enhancement (CAPLE), was set up in March 2016. Cognizant of the benefits of life-wide learning, independent learning and collaborative peer learning, CAPLE offers a series of workshops and various kinds of English and culture learning activities that adopt these pedagogical approaches.

Centre usage figures and user feedback were continuously collected for evaluative purposes. Data collected through student diaries, online surveys, usage records of the online programmes and other resources and a focus group interview showed varying levels of popularity of different types of workshops/activities, suggesting there is a need for programme designers to have a more realistic view about students' actual English learning needs and learning motivation. Recommendations are made accordingly for more economical use of resources.
\end{abstract}

Keyword: English language enhancement, programme design, instrumental motivation, Hong Kong, higher education

\section{Background}

\subsection{Inadequate English Proficiency for Tertiary Studies}

Under the forces of globalization, English has become ever more important as a medium of communication for business, academic, professional and social purposes, and there is little doubt that mastery of the language can provide a competitive edge for college graduates in their future pursuits. However, English is often treated as a school subject with a set syllabus in secondary schools in Hong Kong, which may make it difficult for students to see its relevance to their future careers, further studies or social life. Misunderstanding of the nature of the subject may lead to the adoption of an inappropriate and ineffective approach to English learning, resulting in a vicious cycle of frustration and demotivation. Therefore, as students reach a tertiary level of study, many of them find their English inadequate for the heightened demand for a strong command of the language for academic and professional purposes, especially for those who come from schools with Chinese as the medium of instruction. This is reflected by their struggle in courses requiring substantial use of English and in obtaining the required results in English tests and examinations; the problem is more acute upon graduation when a real need arises for them to use English accurately and effectively in professional contexts.

With such observations, our college established the Centre for Academic and Professional Language Enhancement (CAPLE) in order to raise its students' general English proficiency. Starting as a project funded by the Quality Enhancement Support Scheme (QESS) of the Hong Kong Education Bureau, CAPLE is tasked with coordinating and organizing a spectrum of activities and providing language support services. Its main goal is to 
rekindle students' interest in learning English by cultivating an English-rich environment that encourages self-access and collaborative learning, while boosting their proficiency by providing individual guidance and support in their development of both academic and professional language skills.

CAPLE is facilitated with computers and projectors for teaching and learning activities and installed with a range of multi-media learning resources for teaching and self-access learning. The centre is manned by Language Officers, who are also responsible for teaching courses, leading activities and providing consultation services. Below is a summary of services provided by CAPLE.

For new students:

- $\quad$ A placement test for all Year 1 students held at the beginning of every semester;

- English enhancement courses to be recommended to students based on their results in the placement test and in the English subject in the Hong Kong Diploma of Secondary Education (HKDSE) examination.

For all students:

- Online English learning resources for self-access learning;

- A language laboratory with 15 computers to facilitate self-access learning;

- A learning management system (LMS) for monitoring students' learning progress over the semesters;

- Language and culture learning activities for life-wide learning;

- Workshops on English for Specific Purposes (ESP Workshops);

- The Peer Language Mentorship Programme for peer learning through regular mentor-mentee gatherings.

The rationale behind the choice and design of services and activities is to bring together the merits of life-wide learning, independent learning and collaborative peer learning, as well as providing individual guidance in specific areas of language use. These pedagogical approaches have been shown by research to have positive cognitive and affective effects on learning as will be discussed below.

The effectiveness of CAPLE's overall programme over the project period was evaluated through qualitative and quantitative data collected from a variety of sources. This paper presents findings from the evaluation, based on which recommendations are made.

\subsection{Theoretical Foundation of CAPLE's Programme}

CAPLE's programme was designed in an eclectic approach, which capitalizes on techniques and activities from a variety of approaches and methodologies, rather than relying on one (River, 1981). Such an approach lends the teacher and the course designer flexibility in addressing the learners' needs and is highly recommended by many language educators (e.g. River, 1981; Yorio, 1987; Hutchinson \& Waters, 1987). The various components of CAPLE's programme were designed based on learning theories and approaches with strengths that were considered to help achieve the overall objectives of fostering students' interest in learning English and ultimately enhancing their academic and professional English language skills.

One major mission of CAPLE is to facilitate students' acquisition of English through life-wide learning activities. Life-wide learning is informal learning that takes place in different environments and through diverse experiences that students may encounter in their lives beyond conventional classroom settings and in socialization (Desjardins, 2003; Leung, 2008; Rubin, 2002). As part of the paradigm of life-long learning, life-wide learning has been increasingly recognized as being able to stimulate students' overall personal, cognitive and social development, and is often incorporated in higher education in order to prepare graduates for the challenges of the complex world (Soylu \& Yelken, 2014). In the context of language learning, this may translate as a wide range of activities in various settings that can foster the development of students' overall ability to use the target language for real-life purposes other than assessments. Such activities could include general interest workshops conducted in English, casual chats on everyday topics and current issues, educational outings, sporting events, and peer mentoring. The concept of life-wide learning permeates through CAPLE's many activities, such as the Coffee Tasting Workshop held in a nearby coffee shop, the Dining Etiquette Workshop held at the college canteen, the Bumperman archery and soccer games held in a sports ground outside the college, and the Peer Language Mentorship Programme.

The Peer Language Mentorship Programme, in addition to promoting life-wide learning, also capitalizes on the benefits of peer and collaborative learning. Peer learning is defined as "people from similar social groupings, who are not professional teachers, helping each other to learn and learning themselves by teaching" (Topping, 1996, p. 322). The peer mentor can play the role of a peer tutor, and through the collaborative process of peer 
tutoring, passive and uncritical learners can be transformed into reflective and autonomous ones (Gardiner, 1996) Peer mentoring therefore offers numerous potential benefits in students' learning and growth. In a general sense, mentoring programmes have a number of benefits for both the first year student and the more experienced student mentor. Some of the benefits include academic success (Rodger \& Tremblay 2003), social connections (Pope \& Van Dyke, 1999), and skill development (Treston, 1999). With a special focus on English learning, the Peer Language Mentorship Programme set out to build a language learning community that fosters mutual learning and support. Through necessitating the use of English in all mentor-mentee meetings and other life-wide learning activities, the programme provided an environment that could contribute to students' development in English and English learning skills.

Another major component of the overall programme at CAPLE is the provision of online English learning programmes with learner tracking functions and computer facilities for self-access learning. As tertiary students, it is important for them to be able to manage their own learning and continue to learn on their own at latter stages of their lives, and one of CAPLE's objectives is to nurture such a capacity in students through the provision of independent learning resources. Self-access technologies allow learning to take place outside the classroom, becoming less formal, less institutionalized and more student-controlled (Reinders \& White, 2016). In other words, such online self-access resources can liberalize education in terms of location, pedagogy, formality and locus of control, which are various dimensions of learner autonomy (Benson, 2011). It was hoped that the provision of such self-access facilities at CAPLE could foster the development of learner autonomy among these students, particularly in area of English learning. As a learner who is self-directed in one area may not automatically become autonomous in another, domain-specific support and guidance may be required (Candy, 1991), and the online facilities at CAPLE were established for this purpose.

In line with the belief in the advantages of online self-learning, an online component was incorporated in the English enhancement courses, which were designed for students whose results in the public examinations barely met the minimal admission requirement to their programmes of study. Selected topics and units from the online English learning programmes with learner tracking functions were blended into the regular course materials. By making the completion of these online activities a course requirement, it was hoped that these students would be aware of their own learning needs and appreciate this mode of learning.

Apart from efforts to foster the development of general language proficiency through informal English and culture learning activities, CAPLE also provided help with English for specific purposes (ESP). General English education equips students with the language skills for common contexts, but for English required for specific professional contexts, which is hard to pick up in everyday life, ESP training is necessary (Orr, 2001). It is clear that students of vocational or professional programmes, like those in this college who are mostly training to be professionals in healthcare-related fields, could benefit from some input of more discipline-specific language. CAPLE therefore designed a series of ESP Workshops, catering to the professional language learning needs of the students. Meanwhile, English for academic purposes (EAP) is also considered important for higher education institutions that use English as the medium of instruction (Jordan, 1997), and it has been found that most undergraduates require language support with an academic orientation (Evans \& Green, 2007). As support for EAP is already available in the formal curriculum, the EAP workshops offered by CAPLE mainly focused on the preparation for the International English Language Testing System (IELTS), a standardized English assessment in which they need to obtain a required result in order to fulfill one of the graduation requirements. These workshops all aimed to provide more specialized and practical English support.

In order to identify students who may need more help with their English learning, a Placement Test was administered on all Year 1 students. The results were meant to provide reference not only for the teachers but also for the students themselves. Those who did not perform well in the test were encouraged to take an online English enhancement course specifically designed for them, and it was hoped that the realization of their own inadequacy would prompt them to seek help early on in their studies, from CAPLE if not other sources.

\section{Data Collection}

The main purpose of data collection for this project was to gather evidence for the evaluation of the implementation of the overall programme, and where possible, the effects of the various components on individual students' learning. As CAPLE is a setup to promote informal learning, and participation is voluntary, the evaluation mainly focused on students' use of the centre facilities and participation in the activities, and their perceptions of them. Students' preferences and comments on individual components of CAPLE's programme would indicate the extent to which the overall approach was effective in generating interest in English learning among the students, and would provide references for future programme design. 
Data were collected mainly through the Student Diaries and surveys, which covered all major aspects of CAPLE. Other methods were also used for some components, such as Facebook for the life-wide learning activities, and a focus group interview for the Peer Language Mentorship Programme (Table 1).

Table 1. Components of CAPLE's programme and methods of data collection

\begin{tabular}{|c|c|c|}
\hline Focus/Purpose of activity & Activity held & Data source \\
\hline $\begin{array}{l}\text { Assessment of beginning } \\
\text { level (Needs analysis) }\end{array}$ & Placement Test & Placement Test results \\
\hline \multirow[t]{2}{*}{ Life-wide learning } & $\begin{array}{l}\text { Fun and culture learning } \\
\text { activities }\end{array}$ & $\begin{array}{ll}\text { - } & \text { Participation numbers } \\
\text { - } & \text { CAPLE Surveys }\end{array}$ \\
\hline & $\begin{array}{l}\text { e.g. Coffee Chat, Coffee } \\
\text { Workshop }\end{array}$ & $\begin{array}{ll}\text { - } & \text { Student Diaries } \\
\text { - } & \text { Facebook comments }\end{array}$ \\
\hline Collaborative peer learning & $\begin{array}{l}\text { Peer Language Mentorship } \\
\text { Programme }\end{array}$ & $\begin{array}{ll}\text { - } & \text { Participation figures } \\
\text { - } & \text { Mentor-mentee Meeting Log Sheets } \\
\text { - } & \text { Focus group interview }\end{array}$ \\
\hline Self-access learning & $\begin{array}{l}\text { Online English Learning } \\
\text { Programmes with } \\
\text { tracking functions }\end{array}$ & $\begin{array}{ll}- & \text { Usage figures } \\
- & \text { CAPLE Surveys } \\
- & \text { Independent Learning Log Sheets }\end{array}$ \\
\hline \multirow[t]{4}{*}{$\begin{array}{l}\text { Help with academic and } \\
\text { professional English }\end{array}$} & ESP Workshops & $\begin{array}{ll}- & \text { Participation figures } \\
\text { - } & \text { Surveys }\end{array}$ \\
\hline & IELTS Workshops & $\begin{array}{ll}\text { - } & \text { Participation figures } \\
\text { - } & \text { Surveys }\end{array}$ \\
\hline & English enhancement courses & $\begin{array}{ll}- & \text { Course evaluations } \\
\text { - } & \text { Surveys }\end{array}$ \\
\hline & Individual consultations & $\begin{array}{ll}- & \text { CAPLE Surveys } \\
- & \text { Observations by officers }\end{array}$ \\
\hline Overall centre usage & & $\begin{array}{ll}- & \text { Student Diaries } \\
- & \text { CAPLE surveys } \\
- & \text { Observations by officers }\end{array}$ \\
\hline
\end{tabular}

Results across the different data sources were put together for interpretation and analysis. Observations by the language officers and members of the implementation team, who were in constant and direct contact with users of CAPLE, were also used to illuminate findings from the sources above.

\section{Results and Findings}

Results and findings reported here were mainly derived from data collected between March 2016 to May 2017 through the Student Diaries, usage records, online surveys and a focus group interview (Table 2):

Table 2. Data collected from March 2016 to May 2017

\begin{tabular}{ll}
\hline Data source & Number of respondents/participants \\
\hline The Placement Test & 297 (AY2016-17 Semester 1); \\
& 170 (AY2016-17 Semester 2) \\
Student Diaries (Collected from individuals on each of their & Number of visitors to CAPLE (March 2016 - \\
visits) & $\begin{array}{l}\text { May 2017): 366 } \\
\text { Total number of visits: 1027 }\end{array}$ \\
\hline
\end{tabular}


CAPLE Survey (Sep 2016 - Jan 2017)

\section{3}

$\begin{array}{ll}\text { Survey on English Enhancement Course Level } 1 \text { (ENG0100) } & 19 \\ \text { Survey on English Enhancement Course Level 2 (ENG0200, } & 35\end{array}$

AY1617 Semester 1)

Survey on English Enhancement Course Level 2 (ENG0200, 25

AY1617 Semester 2)

Survey on the Peer Language Mentorship Programme (First 6 cohort)

Survey on the Peer Language Mentorship Programme 6 (Second cohort)

Survey on IELTS workshop in May 2017

6

Focus group interview (with participants of the Peer 5

Language Mentorship Programme)

\subsection{Self-access Learning}

\subsubsection{Usage of the Online English Learning Programmes}

The students' self-access learning habits were reflected by the usage of the Online English Learning Programmes. The subscription to Clarity's Online English Learning Programmes began in May 2016, soon after CAPLE started its operation. Usage statistics of the six Online English Learning Programmes reveal similar seasonal patterns of use across these programmes, and it is obvious that Active Reading, Practical Writing, Road to IELTS and Tense Busters recorded higher usage rates (Figures 1-6).

As mentioned, each of the English enhancement courses was designed with an online component. Exercises from the four Online English Learning Programmes above were assigned as self-study materials and homework. It is therefore not surprising that Semester 1 (September to December 2016) and Semester 2 (January to April 2017) were the peak seasons of the use of these programmes. Few students used them during the summer months, except the Road to IELTS programme which recorded 100 or above login times in two of those months.

The monthly usage figures of the other two programmes, Study Skills Success and Pronunciation Sounds, were invariably single digits. In view of the low utilization rate, subscription to these programmes was not renewed after April 2017. While the reasons for the lack of popularity of these programmes were not clearly known, it was apparent that the other four programmes were better utilized because they were required components of the courses. This interpretation is supported by the fact that the login counts of Tense Busters, which shot up to over 600 at its peak, dropped to 10 or below in Semester 2 when the enhancement course offered did not require its use.

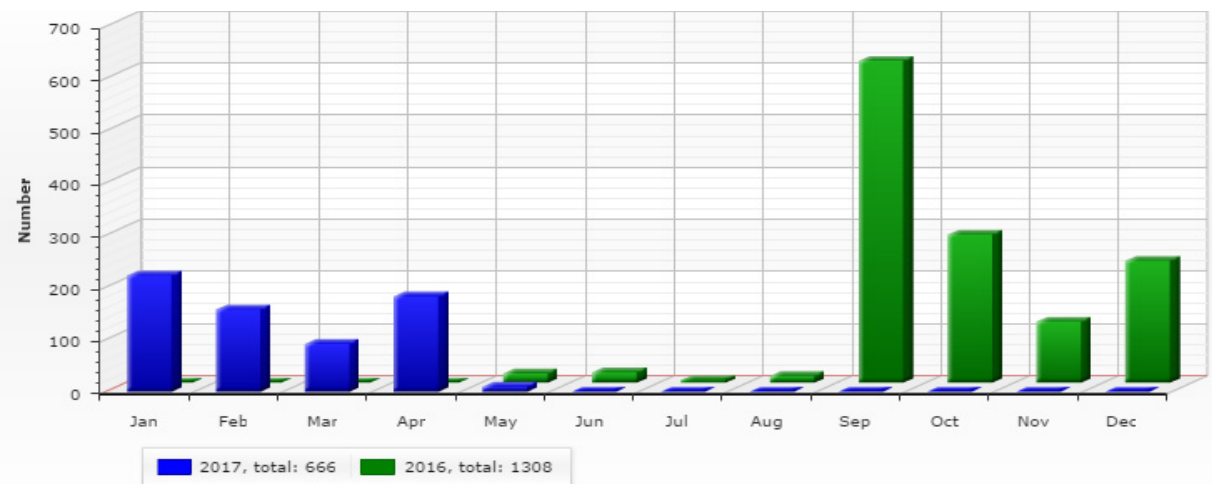

Figure 1. Usage of Active Reading

Note. Actual usage figures of Active Reading are reported below:

\begin{tabular}{lllllllllllll}
\hline \multirow{2}{*}{2016} & JAN & FEB & MAR & APR & MAY & JUN & JUL & AUG & SEP & OCT & NOV & DEC \\
\cline { 2 - 10 } 2017 & N.A. & N.A. & N.A. & N.A. & 18 & 20 & 5 & 13 & 617 & 284 & 117 & 234 \\
\hline
\end{tabular}




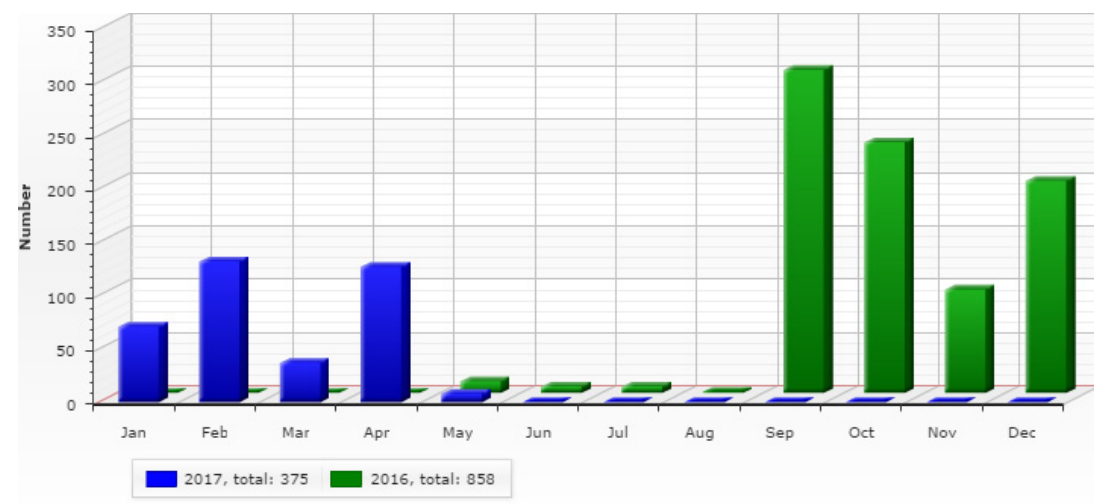

Figure 2. Usage of practical writing

Note. Actual usage figures of Practical Writing are shown below:

\begin{tabular}{lllllllllllll}
\hline & JAN & FEB & MAR & APR & MAY & JUN & JUL & AUG & SEP & OCT & NOV & DEC \\
\cline { 2 - 10 } 2016 & N.A. & N.A. & N.A. & N.A. & 11 & 6 & 6 & 1 & 303 & 235 & 97 & 199 \\
2017 & 71 & 109 & 37 & 127 & 8 & & & & & & & \\
\hline
\end{tabular}

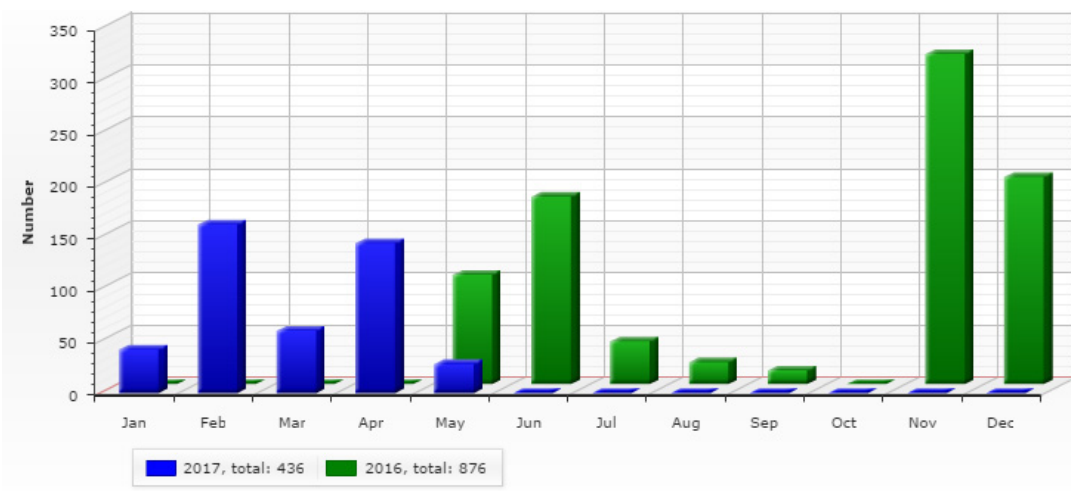

Figure 3. Usage of road to IELTS academic

Note. Actual usage figures of Road to IELTS Academic are shown below:

\begin{tabular}{lllllllllllll}
\hline & JAN & FEB & MAR & APR & MAY & JUN & JUL & AUG & SEP & OCT & NOV & DEC \\
\hline 2016 & N.A. & N.A. & N.A. & N.A. & 105 & 180 & 41 & 21 & 13 & 0 & 317 & 199 \\
2017 & 42 & 152 & 60 & 144 & 28 & & & & & & & \\
\hline
\end{tabular}

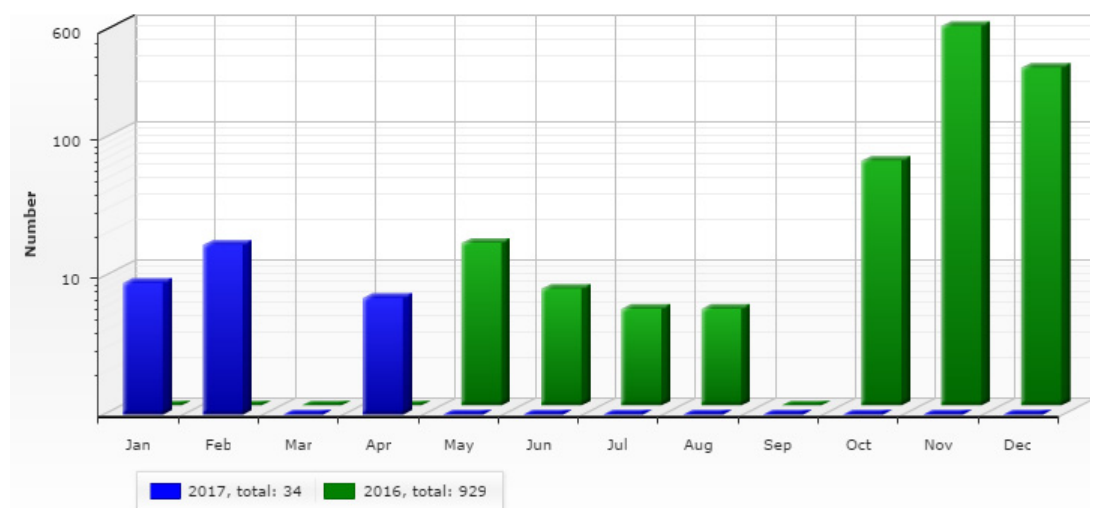

Figure 4. Usage of Tense Busters

Note. Actual usage figures of Tense Busters are shown below: 


\begin{tabular}{|c|c|c|c|c|c|c|c|c|c|c|c|c|}
\hline & JAN & FEB & MAR & APR & MAY & JUN & JUL & AUG & SEP & OCT & NOV & DEC \\
\hline 2016 & N.A. & N.A. & N.A. & N.A. & 15 & 7 & 5 & 5 & 0 & 59 & 558 & 278 \\
\hline 2017 & 9 & 17 & 1 & 7 & 0 & & & & & & & \\
\hline
\end{tabular}

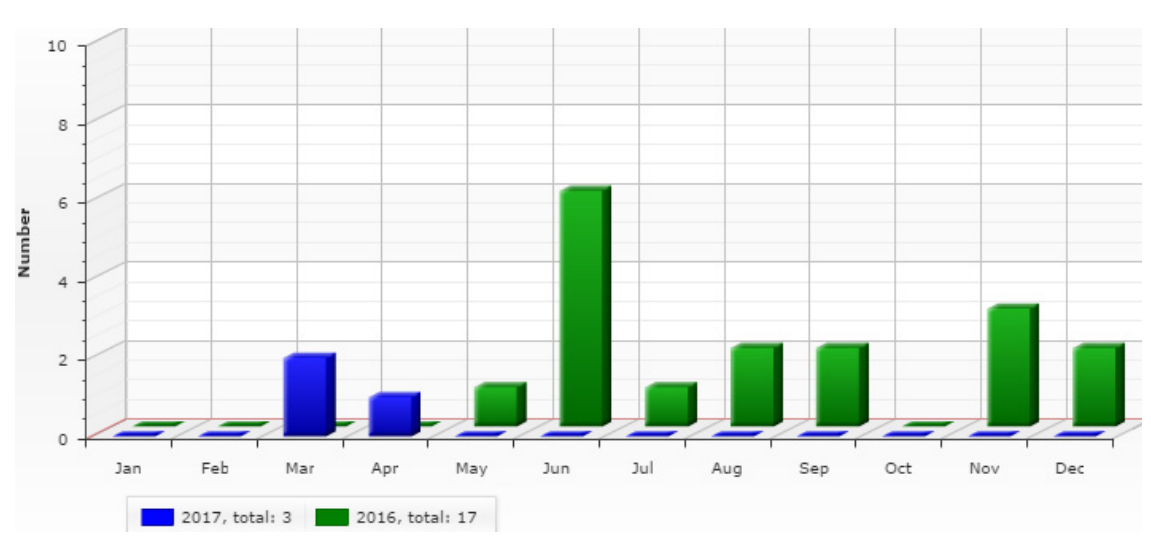

Figure 5. Usage of Study Skills Success

Note. Actual usage figures of Study Skills for Success are shown below:

\begin{tabular}{lllllllllllll}
\hline & JAN & FEB & MAR & APR & MAY & JUN & JUL & AUG & SEP & OCT & NOV & DEC \\
\hline 2016 & N.A. & N.A. & N.A. & N.A. & 1 & 6 & 1 & 2 & 2 & 0 & 3 & 2 \\
2017 & 0 & 0 & 2 & 1 & N.A. & N.A. & N.A. & N.A. & N.A. & N.A. & N.A. & N.A. \\
\hline
\end{tabular}

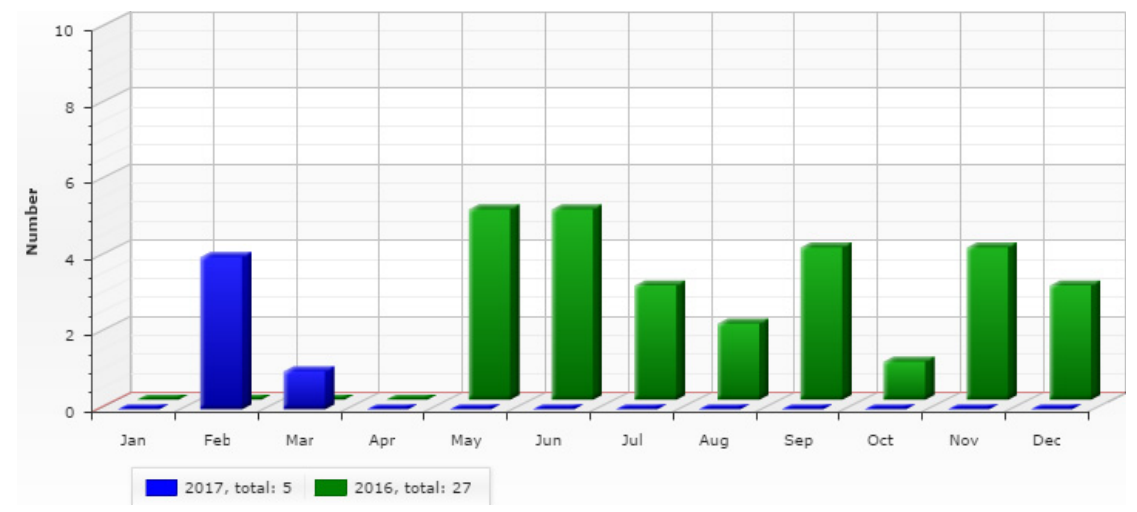

Figure 6. Usage trend of clear pronunciation sounds

Note. Actual usage figures are shown below:

\begin{tabular}{lllllllllllll}
\hline & JAN & FEB & MAR & APR & MAY & JUN & JUL & AUG & SEP & OCT & NOV & DEC \\
\hline 2016 & N.A. & N.A. & N.A. & N.A. & 5 & 5 & 3 & 2 & 4 & 1 & 4 & 3 \\
2017 & 0 & 4 & 1 & 0 & N.A. & N.A. & N.A. & N.A. & N.A. & N.A. & N.A. & N.A. \\
\hline
\end{tabular}

\subsubsection{Student Perceptions of the Online Component of the English Enhancement Courses}

Responses to the questions regarding the online component were very positive across the three surveys on the English enhancement courses, showing that although few students would take the initiative to carry out self-study using the online learning programmes, those who had tried the programmes generally enjoyed the experience. Respondents were asked to rate the following statements on a scale of 5 ( $1=$ strongly disagree; $5=$ strongly agree): 
1. This online component helped me with my learning in this course.

2. The amount of online work assigned was appropriate.

3. The online tasks made learning in this course more fun.

4. The online component should be kept for future cohorts.

The average ratings of all these statements were all above 4.2 across the three surveys, with the exception of the responses to Q.1 and Q.4 in one survey, though the ratings were still high at 3.97 and 3.91 respectively. These show that the Online English Learning Programmes were overall well-received.

\subsection{Life-wide Learning Activities}

\subsubsection{English and Culture Learning Workshops}

By June 2017, 11 fun activities and workshops conducted in English had been held by CAPLE (Table 3). The number of participants tended to be small but sufficient for the activities to proceed as planned.

Table 3. Activities and workshops held by CAPLE from June 2016 to May 2017

\begin{tabular}{llll}
\hline Month & Workshop & Led by & No. of participants \\
\hline Jun 2016 & Movie Night - Zootopia & CAPLE officers & 13 \\
Aug 2016 & Board Game Day & Peer mentors & 7 \\
Sep 2016 & Tiramisu Workshop & Peer mentors & 23 \\
Oct 2016 & Mini Discussion & Peer mentors & 6 \\
Jan 2017 & Banana Boat Ice-cream & Peer mentors & 4 \\
Feb 2017 & Dining Etiquette Workshop & CAPLE officers & 8 \\
Feb 2017 & Colourful Sand Bottle & Peer mentors & 8 \\
Mar 2017 & Coffee Workshop & CAPLE officers & 11 \\
Apr 2017 & Chocolate Factory DIY & Peer mentors & 6 \\
Apr 2017 & Chocolate Factory DIY (re-run) & Peer mentors & 8 \\
Jun 2017 & Bumperman & CAPLE officers & 8 \\
\hline
\end{tabular}

\subsubsection{Coffee Chats}

These were sessions for casual conversations on topics of students' choice or picked by the language officer. The purpose was to provide practice in using English in natural contexts and improve students' vocabularies on common topics of interest. These sessions were held by native English-speaking tutors who did not know Chinese, so there was a genuine need for students to chat with them in English. The enrolment numbers were constantly low, with none or only a few participants every month, reflecting students' rather low incentive to practise oral English.

\subsection{Academic and Professional English Support}

\subsubsection{IELTS Workshops}

CAPLE held IELTS workshops over the summer months in 2016, and these workshops were mostly full (See Table 4 for total number of workshops and participants). In view of the popularity of these workshops, CAPLE started to offer IELTS workshops earlier in 2017, starting in March. 
Table 4. Number of IELTS workshops and participants

\begin{tabular}{lll}
\hline Date & No of workshops & No. of participants \\
\hline Jun 2016 & 8 & 82 \\
Jul 2016 & 4 & 24 \\
Mar 2017 & 1 (Speaking) & 10 (Online enrolments: 16) \\
May 2017 & 1 (Listening) & 8 (Online enrolments: 15) \\
Jun 2017 & 10 & 50 (Online enrolments as of 1 Jun) \\
\hline
\end{tabular}

The figures alone suggest a strong demand for training in IELTS, and as the available survey data could show, these workshops were generally well received. For example, the overall satisfaction with the speaking and listening workshops held in March and May 2017 were rated as 4.67 (out of 5, n=3) and 4 (out of 5, n=6) respectively, and in both surveys, all the participants expressed their wish to see more IELTS workshops organized by CAPLE. Such a desire for IELTS support was also evidenced by comments on the Student Diaries, such as:

"Yes, I do. I hope there will be more lessons related to IELTS to be provided."

"I really hope there will be an IELTS course earlier e.g. Feb. March."

"Hold more activities and IELTS WS."

"I think providing computers and material for listening is good. It would be better if more IELTS practice books are available in the centre."

The IELTS workshops were indisputably the most sought after activities offered by CAPLE, reflecting these students' need for EAP support as previously discussed.

\subsubsection{ESP Workshops}

Up till June 2017, seven ESP workshops had been held by CAPLE. Unlike the IELTS Workshops, these workshops did not attract a large number of participants, particularly the ones held between March and May 2017 as shown in Table 5 below. The last workshop, the one held in June 2017, was expected to have an exceptionally large audience as it was made a compulsory session in one core course in the early childhood education programme.

Table 5. ESP Workshops and number of participants

\begin{tabular}{lll}
\hline Month & Workshop & No. of participants \\
\hline Jul 2016 & Business English Workshop & 8 \\
Feb 2017 & Application Letter Writing Workshop & 8 \\
Feb 2017 & English for Healthcare Professionals (Workshop 1) & 8 \\
Mar 2017 & English for Healthcare Professionals (Workshop 2) & 2 \\
Apr 2017 & English for Healthcare Professionals (Workshop 3) & 4 \\
May 2017 & English for Healthcare Professionals (Workshop 4) & 2 \\
Jun 2017 & English for Early Childhood Education & 31 (estimate as of 31 May 2017) \\
\hline
\end{tabular}

Whether students attended these workshops on their own accord or were made do so, they all tended to value the experiences. For example, students' overall level of satisfaction with English for Healthcare Professionals (Workshop 1) was high as reflected by an average rating of 4.5 out of $5(\mathrm{n}=8)$. It seems rather unlikely that the drop in participation number in the subsequent workshops was caused by the quality of the first workshop in the series. Although the students may have missed the following sessions for various reasons, their low participation reflected that they did not find the urgency to pick up English specific to their profession. This was compounded by the fact that these workshops were offered in the middle of a semester (March 2017) when students started to be busy with their course work and with their preparation for the final examination. 


\subsection{The Peer Language Mentorship Programme}

The programme recruited members twice during the project period, once in May 2016 and once in September 2016. Participants of each cohort were expected to stay with the programme for six consecutive months before being granted a certificate and community service hours. A training session for mentors and a welcoming party for all members were held near the beginning of each round of the programme. The mentors and mentees were paired up according to their learning needs, and each pair was required to meet up at CAPLE at least once a month. The mentors were also expected to hold activities for the mentees and all other students who may be interested.

As shown in Table 4 above, the activities led by the peer language mentors were all fun workshops on topics related to food and leisure, all suggested by the mentors. However, it seems that even though the ideas came from the students themselves, peer support was not always reliable. In a few cases, the students who proposed the activities withdrew from the programme for personal reasons, leaving the responsibility to implement the ideas to other mentors. This shows the members' commitment was not strong, which also reflects a lack of sense of responsibility.

Despite these difficulties, members of the programme appear to have enjoyed the experience as shown by the results of the surveys administered upon completion of each round of the programme. There were altogether 17 participants from the two cohorts of the programme, 9 from the $1^{\text {st }}$ round and 8 from the $2^{\text {nd }}$ round. There were 6 respondents in each survey, contributing to response rates of over 50 percent. Data collected from the two surveys reflected positively on the effectiveness of the programme. Respondents mostly agreed with the statement "I have a better understanding how mentoring works", with an average rating of 4 out of 5 in both surveys. In addition, $100 \%$ of the respondents chose "maybe" to "definitely will" in response to the question "After your experience of the programme, how likely are you to recommend it to a friend?" indicating that it was to a certain extent a fulfilling experience.

Data collected through the focus group interview concurred with findings from the survey. Of the 12 participants who had completed the surveys, five agreed to participate in a focus group interview. Three of them were mentees ( 2 females, 1 male) and two were mentors ( 1 female, 1 male). All of them agreed that their expectations had mostly been met. Three of them rated the programme as A- to A; one rated it as $\mathrm{B}+$, and one as $\mathrm{B}-$. The one who rated it as B- expressed a little disappointment over the fact that his mentee had a lot to share and taught him vocabulary on life-wide topics instead of him being the one carrying out most of the tutoring. However, after some discussion he admitted that mentoring is a two-way rather than one-way process and both the mentor and mentee should benefit from the process. This realization showed that he had reflected on the process and undergone some personal growth. Each other member also mentioned something they had learnt from the programme, such as time management skills, communication skills and knowledge of the English language.

The focus group interview elicited responses that not only provided useful feedback on the design of the programme and activities but also helped explain the low participation rates of some of CAPLE's activities. When asked to suggest activities for future, none could come up with ideas that the others would unanimously agree; it seemed that these students had very diverse individual interests. All participants however seemed to agree that they would join an activity if they "were interested and had time". Then they brought up the issue of the difficulty to make time for the fun learning activities at CAPLE outside of their schoolwork, part-time work and other interests they pursued off-campus. They also agreed that students generally would rather not come back to the college for these activities if they did not have class. One student finally said, "It is all about priority. If we are really interested, we will make time for it." When asked whether the fun activities at CAPLE were of low priority, he nodded. The others all nodded in agreement. Their hesitation and embarrassment in answering these questions provided clues as to why for most of the activities, participant recruitment was rather difficult.

When asked how to encourage students to participate in the activities, the participants suggested surveying students' interests at the beginning of the programme. They also proposed making participation in CAPLE activities one of the graduation criteria so that students would make time for it. Similar comments were also found in the Student Diaries. These reveal that while these students did not altogether dismiss CAPLE's activities, they knew that their fellow students, perhaps even they themselves, would rather not spend time on these activities unless they had to.

\subsection{Overall Usage of CAPLE}

The usage of CAPLE, like that of the Online English Learning Programmes, was seasonal (Table 6). Generally the centre had more visitors in March and April, right before the examination period when they needed a place for project work and examination preparation. The usage picked up noticeably in June in 2016, largely because 
of the increase in the number of participants in the IELTS Workshops held at CAPLE.

Table 6. Usage figures of CAPLE

\begin{tabular}{lllllllllllllll}
\hline & Jan & Feb & Mar & Apr & May & Jun & Jul & Aug & Sep & Oct & Nov & Dec & & Total \\
\hline 2016 & N.A. & N.A. & 22 & 95 & 59 & 119 & 37 & 10 & 55 & 60 & 110 & 77 & & 644 \\
2017 & 44 & 84 & 113 & 137 & 34 & & & & & & & & $1 *$ & 413 \\
As of May 2017 & 44 & 84 & 135 & 232 & 93 & 119 & 37 & 10 & 55 & 60 & 110 & 77 & & 1057 \\
\hline
\end{tabular}

*Information not given found on the form.

From the students' reasons for coming to CAPLE and their comments about the place, it is quite clear that most of the students liked CAPLE, but not in its official capacity as a language centre. Regarding their purposes of visiting CAPLE, 512 of the visits were for using the common area. Other more common purposes were to use the computers, accounting for 264 of the visits, followed by hanging out/taking a break, chatting with the English teachers and using the English learning facilities, each contributing to around 150 visits. Apparently, these students all liked the learning space provided by CAPLE. There were 47 positive entries in the Student Diaries commenting directly on the "peaceful" or "nice" environment of the centre, such as:

"I like it, it is lot more quiet than the other common area and the environment is really great for learning."

"Good place, quiet."

"Yes. CAPLE let me pay attention and provides a silent place."

"I love here, so quiet! Can study \& learn English can faster."

From the figures and responses summarized above and from the officers' observations, most students came to CAPLE to use the facilities rather than for English learning, except when they wanted to use the IELTS resources or needed the officers' help with their IELTS preparation. When students go to a centre dedicated to English learning not for learning or practicing the language, they probably would not spend much time on polishing their English elsewhere.

\subsection{Observations by CAPLE Officers and Project Implementation Team Members}

\subsubsection{Difficulty in Recruiting Participants}

Recruitment of participants for the workshops and activities became particularly difficult towards mid-term as the students started to be more occupied with coursework. After the second semester, many would be engaged in their practicum work; others would find part-time work or have travel plans. During the semester, even though Wednesday afternoons were reserved for meetings and no class was scheduled for those timeslots, students would still not be available as they would schedule in part-time work or other personal activities. When asked why they did not join the activities, the reasons given were mostly "no time" or "time clashes with lessons". In other words, there was not too much room in the students' calendars for CAPLE's activities, and it was practically impossible to find a time when most of the students would be available.

Even if students enroll in an activity, they may decide not to turn up at the last minute for various reasons. This happened to most of the activities. For example, some students signed up for the Peer Language Mentorship programme but never turned up once. As another example, the IELTS Listening Workshop held in May 2017 had 15 enrolments according to the online enrolment system, and only 8 actually turned up.

\subsubsection{Difficulty in Feedback Collection}

Participants of the fun activities were all requested to post their comments on Facebook after the events for sharing with the wider community. This was however difficult as students would usually leave right after or even before the end of the activities; even though some of them promised to as asked, most of them would not do so without being repeatedly prompted by the teachers or officers, and many would simply click "Like". Similarly, the open-ended questions in the surveys only managed to elicit a few meaningful responses.

\subsubsection{Motives to Seek Consultations}

During term time, there were a few student consultation requests every week, but when the semester broke, there were usually no student visitors. The main purpose of these sessions was to get IELTS practice. Other less common purposes were to seek the officers' help in editing their assignments, projects or application letters. 


\section{Discussion}

\subsection{Effectiveness of the Programme}

Although the participation numbers of CAPLE's activities were generally not high, there was continuous support from a few enthusiastic students at any given time. In particular, the IELTS workshops were mostly full and quite well sought after, and some of the other workshops also had close to or above 10 participants. There was also evidence to show that those who actively participated in CAPLE's activities, particularly the Peer Language Mentorship Programme, benefitted academically and personally from the experiences. In addition, the centre usage in the second year of its operation had noticeably increased as more students learnt about the centre, and students' feedback on the various components of the programme was consistently positive. These show that the centre was functioning well and gradually developing. Overall, the programme appeared to be a mild success, demonstrating the viability of its overall approach.

Perhaps more valuable findings from the CAPLE experience were not only what activities the students preferred, but also the reasons behind these preferences. Apart from reflecting the level of success of the implementation of the project, the findings above also shed some light on the nature of tertiary students' motivation in learning English. A better understanding of these students' motives and attitudes towards English learning may help English teachers and curriculum designers to realize the constraints they may need to overcome in this new age.

\subsection{Motivation to Learn English among Tertiary Students}

The low participation rate of CAPLE's English and culture learning activities, such as Coffee Chat and the Etiquette Workshop, clearly indicates that these students were mostly not intrinsically motivated to learn English and western culture. Learners driven by intrinsic motivation would enjoy using and learning the language (Deci \& Ryan's, 1985, 2002); the life-wide learning activities organized by CAPLE, involving native English speakers and immense interaction in the language, should have been a draw and attracted larger crowds as the IELTS workshops did, but this was not the case. This means that the majority of the students in this college would not seek out opportunities to learn the language voluntarily. In other words, most of these students were not genuinely interested in English.

The nature of motivation aside, there may also be a general lack of motivation among these students. As shown in many studies, there are close ties between motivation, particularly intrinsic motivation and self-initiation in language learning (e.g. Deci \& Ryan, 1994; Ushioda, 1996, 2006; Yeung, 2016). The generally low participant rates of the workshops, the students' readiness to drop the centre's activities for other causes, the lack of initiative to use the online resources and the centre facilities for their intended purposes, all allude to the students' unwillingness to invest time on general English learning. Given that autonomous learners are essentially motivated learners (Ushioda, 1996), the lack of self-initiation by these learners may reflect their low level of motivation concerning the learning of English.

However, it may not be fair to say that these students are entirely unmotivated to improve their English; they would make an effort when there are practical and immediate needs, as shown by their active participation in the IELTS workshops and consultation sessions, mainly prompted by the need to fulfill a graduation requirement, and also the relatively higher participation numbers in the more practical Application Letter Writing Workshop and the Business English Workshop. These relatively popular workshops were mainly attended by senior-year and final-year students, who were preparing to graduate and seek further education or employment right afterwards, thus the need and motivation to brush up their English. In addition to these practical needs, students could also be pushed by other factors to join English learning activities, such as the need to fulfill a course requirement. The online component of the English enhancement courses, and the English enhancement courses themselves, are typical examples of how students could be receptive to demands for them to work on their English imposed upon them by the institution, and how they may even become appreciative of the experiences. The students' active participation in the practical workshops and willingness to complete the prescribed courses and materials show that when English learning is directly linked to some requirements or real-life purposes, these tertiary students can become motivated. This means that for tertiary students, or at the very least for many of those in Hong Kong, English learning is quite often propelled not by intrinsic or integrative reasons but by instrumental reasons. This finding concurs with those in studies conducted in other contexts (e.g. Liu, 2007; Fryer et al., 2013), showing that tertiary students generally take a utilitarian approach to English learning; they know what the requirements are and are economical with their efforts in achieving those clearly-defined goals.

The lack of self-motivation in English learning may be explained by students' general level of English proficiency. With the expansion of tertiary education since the 1990s, the number of college students has increased substantially, inevitably lowering the average academic and language standards of tertiary students. In 
this particular case, the sheer number of students required to take the English enhancement courses indicates that many of the new students entered the college with barely acceptable results in the English subject in public examinations, mainly the Hong Kong Diploma of Secondary Education (HKDSE) examination. The lack of success in English learning over the years may have affected their self-confidence and eroded their motivation, particularly intrinsic motivation in English learning before they entered tertiary education. This is a vicious cycle as low self-efficacy can lead to low motivation and subsequently failure (e.g. Graham, 2003) and disengage learners from subjects in which they believe they cannot succeed in (e.g. Breen \& Lindsay, 2002). This may not be easily remedied within a short period of time, and not without persistent effort by the students themselves and by the college or university.

\subsection{The Perceived Importance of English Learning}

Another reason for their lack of motivation in English learning may be the perceived low importance of English compared with the core subjects. Although English is a required subject in most undergraduate programmes, and English communication competence is regarded by many employers as one of the attributes that graduates need to be equipped with (e.g. Education Bureau, 2010; Li, 2015), most tertiary students may not take English and other general education subjects seriously. Students tend to conceive employability skills to be vocational and technical skills (William, 2015), and they are reluctant to spend time on general education subjects (FSTE, 2013; Fuess \& Mitchell, 2011; Seraphin, 2013). This is particularly true for students studying for professional degrees, such as those in this college. When they believe a professional qualification guarantees employment in the future, it is not hard to understand why they would not want to spare time for non-disciplinary subjects.

While the disciplinary subjects undoubtedly take precedence, there are other pursuits that generic subjects like English need to compete with for students' time. For one, many students take up part-time work out of necessity to finance their studies, or out of the desire to make money for luxury items. There are numerous activity options outside of the school that students can choose to take up for fun or for their own life-wide learning. Besides studying, there are many other obligations and entertainment activities that students need to fit in their busy schedules. English learning is inevitably low on these students' priority lists, as admitted by the participants in the focus group interview, and it is unrealistic for them to give up those other pursuits for learning English at school.

\subsection{The Need for Coordinated Efforts to Promote English Learning at Tertiary Level}

Generally uninterested in learning English, and not realizing the importance of English to their future career development, students may easily ignore the incentives to help them learn English on campus. Their English learning needs exist all the same, and it is the role of the college or university to alert them to such needs and provide them with the right kind of support. This may take continuous efforts to assess students' needs and address them with appropriate approaches, and such efforts can be coordinated by a unit dedicated to the purpose, such as CAPLE.

Although the students themselves may not appreciate the importance of English and do not seem to have any active thoughts on how to learn it, these may be altered with organized efforts on the part of the college. As discussed above, when the use of the Online English Learning Programmes were made mandatory, the students could appreciate the usefulness of the programmes which they would not have tried otherwise; when the students participated in the fun activities, they would really engage in them and leave positive feedback afterwards. It is also obvious that students take IELTS or other high-stake English assessments seriously. In other words, these students need others to decide for them what is important to learn and how to learn it. For students lacking intrinsic motivation, external regulation may be necessary in prompting them to action.

A centre like CAPLE can help prescribe how students learn English. It can help enhance the English learning environment on campus through creating and upholding an informal English curriculum and promoting its synergy with the formal English curriculum and with other disciplines. In Hong Kong, English is the medium of instruction of most, if not all, tertiary institutions, so its learning does not need to be confined to the English lessons. If English activities are designed such that they are directly related to students' learning in the formal English courses and their disciplinary courses, and if such activities are integral parts of students' coursework, then English learning would be regarded as more important and more relevant by both other subject teachers and the students. If English requirements are emphasized throughout the years and across the programmes, students will take the learning of English as being for their own good.

\section{Conclusion and Recommendations}

The CAPLE venture was overall a moderate success in view of the continuous support received from the 
students, albeit a small number of them. The general lack of motivation among these students may have affected the overall impact of the pedagogical approaches that the CAPLE programme drew upon, but those who engaged in the programme evidently benefitted from it. Overall the use of such an eclectic approach was effective not only in meeting students' diverse needs, but also in identifying their learning preferences and motives.

While motivation could be nurtured, the CAPLE experience shows that it may not be practical to expect students' interest in English learning to be boosted in a short time. As tertiary students' English learning motivation tends to be instrumental, designers of the English curriculum may not be able to count on students' voluntary engagement in learning activities that are not directly related to their immediate study needs. Therefore, in addition to providing impetus to take part in life-wide English learning activities, designers of English enhancement programmes may also tap into the learners' natural learning motivation by providing instrumentally-oriented English input. It may be more worthwhile and effective to concentrate on the provision of EAP and ESP support services.

Programme designers may also acknowledge the necessity to exert pressure on students to continue with their English learning, and design programmes that tie in with their academic and professional goals. Based on our experience from the CAPLE project, we would like to make the following practical suggestions for other English curriculum designers' reference:

\section{1) Making the activities mandatory}

For students who are not naturally inclined to learn English, ordinary incentives like free refreshments or free gifts would not be sufficient incentives for them to join English learning activities. Such activities can be made compulsory as part of a course, the pre-requisite of a course or a college requirement. As one student suggested, we can make it compulsory for every student to spend a certain amount of time at CAPLE.

2) Providing more directions and guidance for self-learning

Students may not be self-directed enough to decide how to use the self-learning materials and what to discuss with their peer mentors/tutors. Tutors can provide students with a simple syllabus or schedule, or better still, advising or counseling services.

3) Laying more focus on academic and practical English

Workshops providing practice in academic English for tests such as IELTS and help with English for regular courses are more likely to attract attendants, as our experiences show. English support for professional and practical purposes may also appeal to students if they realize how this may relate to their work and study.

4) Conducting more vigorous needs analysis

Tutors may not fully know students' real preferences concerning activities for informal learning. It would be advisable to gather ideas from students themselves. Some of the ideas our students preferred include cooking activities, board games, excursions, sports games (e.g. dodgeball), wild camps and exchange programmes.

5) Maximizing student involvement in organizing activities

With student involvement, there is a guaranteed support base for an activity. Increased ownership of the event would also encourage student engagement.

6) Reaching out to students in the right channels

Facebook is no longer the most popular social media among young people, according to our students. Instagram and We Chat are more commonly used now, but this may change. Trying to reach out to students on popular digital platforms may be an important way, but a peer's or a tutor's personal recommendations quite often work more effectively.

It is hoped that the CAPLE experience and the recommendations made above may be useful to other English curriculum or programme designers who would like to find effective ways to help their students learn. Pedagogical theories may provide useful frameworks, but contextual variations and preferences of target learners may also need to be given serious consideration in actual practice. After all, no programme can work without willing participants however good the design and intentions are.

\section{Acknowledgements}

This paper reports findings from the project titled "The Centre for Academic and Professional Language Enhancement (CAPLE)" funded under the Quality Education Support Scheme [Project Ref.: EDB(EF) 4/7/2041/10 Pt.1 (2015)] by the Education Bureau of the Government of the Hong Kong Special Administrative Region of China. 


\section{References}

Benson, P. (2011). Language learning and teaching beyond the classroom: An introduction to the field. In P. Benson, \& H. Reinders (Eds.), Beyond the language classroom (pp. 7-16). Basingstoke, UK: Palgrave Macmillan. https://doi.org/10.1057/9780230306790

Breen, R., \& Lindsay, R. (2002). Different disciplines require different motivations for student success. Research in Higher Education, 43, 639-725. https://doi.org/10.1023/A:1020940615784

Deci, E. L., \& Ryan, R. M. (1985). Intrinsic motivation and self-determination in human behavior. New York: Plenum Press. https://doi.org/10.1007/978-1-4899-2271-7

Deci, E. L., \& Ryan, R. M. (1994). Promoting self - determined education. Scandinavian journal of educational research, 38(1), 3-14. https://doi.org/10.1080/0031383940380101

Deci, E. L., \& Ryan, R. M. (2002). Handbook of self-determination research: Theoretical and applied issues. Rochester: University of Rochester Press.

Desjardins, R. (2003). Determinants of economic and social outcomes from a life-wide learning perspective in Canada. Education economics, 11(1), 11-38. https://doi.org/10.1080/09645290210127462

Education Bureau. (2010). Survey on Opinions of Employers on Major Aspects of Performance of Publicly-funded First Degree Graduates in Year 2006. Hong Kong.

Evans, S., \& Green, C. (2007). Why EAP is necessary: A survey of Hong Kong tertiary students. Journal of English for Academic Purposes, 6, 3-17. https://doi.org/10.1016/j.jeap.2006.11.005

Fryer, L. K., Ozono, S., Carter, P., Nakao, K., \& Anderson, C. J. (2013). Instrumental reasons for studying in compulsory English courses: I didn't come to university to study English, so why should I? Innovation in Language Learning and Teaching, 8(3), 239-256. https://doi.org/10.1080/17501229.2013.835314

Gardiner, R. (1996). Supplemental instruction (SI). Academic Staff Development Unit, Queensland University of Technology.

Graham, S. J. (2003). Learners' metacognitive beliefs: A modern foreign languages case study. Research in Education, 70(1), 9-20. https://doi.org/10.7227/RIE.70.2

Federation for Self-Financing Tertiary Education. (2013). General Education Guidebook. Hong Kong: Federation for Self-Financing Tertiary Education.

Fuess S. M., \& Mitchell, N. D. (2011). General Education Reform: Opportunities for Institutional Alignment. The Journal of General Education, 6(1), 1-16. https://doi.org/10.1353/jge.2011.0000

Hutchinson, T., \& Waters, A. (1987). English for specific purposes: A learning-centred approach. Cambridge: Cambridge University Press. https://doi.org/10.1017/CBO9780511733031

Jordan, R. R. (1997). English for academic purposes: a guide and resource book for teachers. Cambridge, UK and New York, NY: Cambridge University Press. https://doi.org/10.1017/CBO9780511733062

Leung, W. L. A. (2008). Teacher Concerns about Curriculum Reform. The Asia-Pacific Education Researcher, 17(1), 75-97. https://doi.org/10.3860/taper.v17i1.351

Li, T. (2015). Required graduate attributes in Hong Kong and their relative importance. European Scientific Journal, 11(34), 536-561.

Liu, M. (2007). Chinese students' motivation to learn English at the tertiary level. Asian EFL Journal, 9(1), 126-146.

Orr, T. (2001). English language education for specific professional needs. IEEE transactions on professional communication, 44(3), 207-211. https://doi.org/10.1109/47.946467

Pope, G., \& Van Dyke, M. (1999). Mentoring....Value adding to the University. Journal of the Australian and New Zealand Student Services Association, 13, 15-27.

Reinders, H., \& White, C. (2016). 20 years of autonomy and technology: How far have we come and where to next? Language Learning \& Technology, 20(2), 143-154.

Rivers, W. (1981). Teaching foreign-language skills (2nd ed.). Chicago, Ill.: University of Chicago Press.

Rodger, S., \& Tremblay, P. F. (2003). The effects of a peer mentoring program on academic success among first year university students. Canadian Journal of Higher Education, 33(3), 1-17. 
Rubin, A. (2002). Futures Learning: from eLearning towards a Futures-oriented Way of Learning. Journal of Futures Studies, 7(2), 21-34.

Seraphin, C. (2013). General Education Requirements. What's the Point? CollectXpress.com, 20-21.

Soylu, B. A., \& Yelken, T. Y. (2014). A New and Dynamic Phenomenon for Higher Education: Life-wide Learning. Procedia - Social and Behavioral Sciences, 116, 2702-2706. https://doi.org/10.1016/j.sbspro.2014.01.639

Topping, K. J. (1996). The effectiveness of peer tutoring in further and higher education: a typology and review of the literature. Higher Education, 32(3), 321-345. https://doi.org/10.1007/BF00138870

Treston, H. (1999). Peer mentoring: Making a difference at James Cook University, Cairns - It's moments like these you need mentors. Innovations in Education and Training International, 36, 236-243. https://doi.org/10.1080/1355800990360309

Ushioda, E. (1996). The role of motivation. Dublin: Authentik Language Learning Resources.

Ushioda, E. (2006). Motivation, autonomy and sociocultural theory. In P. Benson (Ed.), Learner autonomy 8: Insider perspectives on autonomy in language learning and teaching (pp. 5-24). Dublin, Ireland: Authentik.

Williams, A. M. (2015). Soft Skills perceived by students and employers as relevant employability skills (Doctoral dissertation, Walden University).

Yeung, M. (2016). Exploring the Construct of Learner Autonomy in Writing: The Roles of Motivation and the Teacher. English Language Teaching, 9(8), 122. https://doi.org/10.5539/elt.v9n8p122

Yorio, C. (1987). Building multiple bridges: Eclecticism in language teaching. TESL Canada Journal, 5(1), 91-100. https://doi.org/10.18806/tesl.v5i1.519

\section{Copyrights}

Copyright for this article is retained by the author(s), with first publication rights granted to the journal.

This is an open-access article distributed under the terms and conditions of the Creative Commons Attribution license (http://creativecommons.org/licenses/by/4.0/). 